\title{
Efficacy of chimeric molecules directed towards multiple somatostatin and dopamine receptors on inhibition of GH and prolactin secretion from GH-secreting pituitary adenomas classified as partially responsive to somatostatin analog therapy
}

P Jaquet, G Gunz, A Saveanu, H Dufour ${ }^{1}$, J Taylor ${ }^{2}$, J Dong ${ }^{2}$, S Kim² ${ }^{2}$ J-P Moreau ${ }^{2}$, A Enjalbert and M D Culler ${ }^{2}$

Interactions Cellulaires Neuroendocriniennes, UMR6544, Centre National de la Recherche Scientifique, Institut Fédératif Jean Roche, Faculté de Médecine Nord, Boulevard Pierre Dramard, 13916 Marseille Cedex 20, France, ${ }^{1}$ Service de Neurochirurgie, CHU Timone, 264, rue Saint-Pierre, 13385 Marseille cedex 05, France and ${ }^{2}$ IPSEN, Milford, Massachussetts 01757, USA

(Correspondence should be addressed to P Jaquet; Email: jaquet.p@jean-roche.univ.mrs.fr)

\begin{abstract}
Objective: This study compared the potency of a somatostatin receptor (sstr)2-sstr5 analog, BIM23244, of an sstr2-dopamine D2 receptor (sstr2-DAD2) molecule, BIM-23A387 and of new somatostatin-dopamine chimeric molecules with differing, enhanced affinities for sstr2, sstr5 and DAD2, BIM-23A758, BIM-23A760 and BIM-23A761, to suppress GH and prolactin (PRL) from 18 human GH adenomas that are partially responsive to octreotide or lanreotide.

Materials and methods: The sstr2, sstr5 and DAD2 mRNA levels were determined by RT-PCR. The effect of drugs was tested in cell cultures at various concentrations.

Results: In all tumors, the sstr2, sstr 5 and DAD2 mRNA levels were coexpressed (mean levels \pm S.E.M. $0.4 \pm 0.1,5.3 \pm 1.9$ and $2.0 \pm 0.4$ copy/copy $\beta$-glucuronidase). In 13 tumors, the maximal suppression

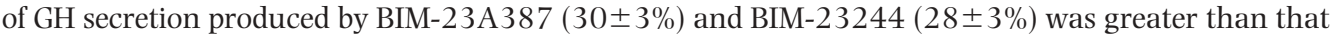
produced by octreotide (23 $\pm 3 \%)$. In six out of 13 tumors, BIM-23A758, BIM-23A760 and BIM$23 \mathrm{~A} 761$ produced greater maximal suppression of $\mathrm{GH}$ secretion than octreotide $(33 \pm 5,38 \pm 2$ and $41 \pm 2$ vs $24 \pm 2 \%$ ). Their $\mathrm{EC}_{50}$ values were 10,2 and $4 \mathrm{pmol} / \mathrm{l}$. BIM-23A761 was more effective than BIM-23A387 in GH suppression (41 \pm 2 vs $32 \pm 4 \%$ ). The new chimeric molecules produced maximal PRL suppression greater than octreotide (62 \pm 8 to $74 \pm 5$ vs $46 \pm 11 \%$ ).

Conclusions: Novel dopamine-somatostatin chimeric molecules with differing, enhanced activity at sstr2, sstr5 and DAD2, consistently produced significatly greater suppression of GH and PRL than either octreotide or single-receptor-interacting ligands in tumors from patients classified as only partially responsive to octreotide therapy. The higher efficacy of the chimeric compounds was, at least partially, linked to their high affinity for sstr2 $\left(\mathrm{IC}_{50} 1-10 \mathrm{pmol} / \mathrm{l}\right)$. The other mechanisms by which such molecules produce an enhanced inhibition of GH remain to be elucidated.
\end{abstract}

European Journal of Endocrinology 153 135-141

\section{Introduction}

Medical treatment of acromegalic patients using the somatostatin (SST) analogs, octreotide or lanreotide, allows effective control of growth hormone $(\mathrm{GH})$ hypersecretion and restores normal plasma insulin-like growth factor-I (IGF-I) values in about $60 \%$ of patients (1). This percentage is likely overestimated as most of the series reported in this meta-analysis selected the patients on the basis of a previous good response to an acute octreotide testing which lowered GH values below $5 \mu \mathrm{g} / \mathrm{l}$. Dopamine (DA) agonists also suppress GH hypersecretion in some acromegalic patients (2). The DA superagonist, cabergoline, allows effective control of GH and IGF-I in $29-39 \%$ of patients $(3,4)$. In some cases, the combination of SST and DA agonists has been shown to be more effective than treatment with the individual SST agonists (5). While the mechanisms underlying an additive effect of SST and DA analogs are not clear, SST receptors (sstr) and DA D2 receptors (DAD2) have been demonstrated under experimental conditions to heterodimerize in the presence of appropriate ligands, and to generate a novel hybrid receptor that more effectively promotes adenylylate cyclase inhibition than activation of the individual receptors (6). In cultures of GH-secreting tumor cells, we have previously observed an additive suppression of GH and PRL secretion produced either by a bispecific 
sstr2-sstr 5 ligand (7) or by a chimeric sstr2 + DAD2 ligand (8) that exceeds the suppression induced by octreotide in the same tumors.

The initial aim of the present study was to compare the efficacy of the sstr2-sstr5 bispecific SST analog, BIM-23244, and the sstr2-DAD2 chimeric molecule, BIM-23A387, in suppressing GH and PRL in 18 consecutive GH-secreting tumors collected from acromegalic patients previously classified as only partially responsive to long-term octreotide or lanreotide treatment. As the data obtained from this part of the study showed that most of the tumors that are partially responsive to octreotide responded to both dual receptor ligands, a new class of chimeric molecules with differing, enhanced affinities for sstr2, sstr 5 and DAD2, was developed and tested in a subset of the GH-secreting tumors from patients partially responsive to octreotide. This latter study demonstrated that the new chimeric molecules with enhanced activity have the greatest efficacy in suppressing both GH and PRL.

\section{Patients and methods}

\section{Patients}

Eighteen acromegalic patients were enrolled in this study which was approved by the Ethics Committee of the University of Aix-Marseille II. They were 15 women and three men aged $37 \pm 3$ years (mean \pm S.E.M.). Initially, all the patients presented with invasive macroadenomas and were first treated with either sandostatin LAR (20-30 mg i.m., monthly) or with somatuline SR (90-120 mg i.m., monthly), for 626 months before surgery. In eight patients, the DA agonist, cabergoline, was added to the SST analog treatment (1.5$3.5 \mathrm{mg}$ per os, weekly). In this series, the mean initial $\mathrm{GH}$ plasma value measured before any treatment $(82 \pm 44 \mu \mathrm{g} / \mathrm{l})$ was only partially lowered by such long-term medical treatments $(37 \pm 6 \mu \mathrm{g} / \mathrm{l})$. In none of the cases did the depot preparations of octreotide or of lanreotide, even with the addition of the DA agonist, cabergoline, normalize either plasma GH or IGF-I values. These treatments were withdrawn at least 1 month before transphenoidal surgery in all patients. After surgery, a portion of each tumor tissue was analyzed for quantitative expression of sstr2, sstr 5 and DAD2 mRNAs. The remainder of each tissue was dispersed for cell culture studies.

\section{Hormone assays}

GH and PRL were measured using commercial immunoradiometric kits (Immunotech, Marseilles, France). Normal GH values ranged from 0.2 to $2.4 \mu \mathrm{g} / \mathrm{l}$, normal PRL values ranged from 1 to $24 \mu \mathrm{g} / \mathrm{l}$ in women and from 1 to $17 \mu \mathrm{g} / \mathrm{l}$ in men. After an ethanol-acid extraction, the plasma IGF-I assay was performed using the IGF-I RIA kit from Nichols Institute Diagnostics (San Juan Capistrano, CA, USA). The normal ranges, according to sex and age, were established by our laboratory.

\section{Compounds}

The BIM compounds were produced and provided by IPSEN (Milford, MA, USA). Their affinities for the different human receptors were calculated from saturation binding assays performed on membrane preparations from transfected CHO-K1 cells expressing the different sstr or DAD2 subtypes, according to a previously published method (9). The individual characteristics of these compounds are listed in Table 1. Octreotide was supplied by Novartis Pharmaceuticals (Basel, Switzerland). The SST analogs were dissolved in $0.01 \mathrm{~mol} / \mathrm{l}$ acetic acid containing $0.1 \%$ purified human serum albumin (Life Technologies Inc., Cergy-Pontoise, France). The DA compounds were initially prepared as $10^{-3} \mathrm{~mol} / \mathrm{l}$ solutions in $0.01 \mathrm{~mol} / \mathrm{l}$ acetic acid and

Table 1 Human sstr and DAD2 binding affinities of the various DA and SST analogs. Data are from radioligand assays using membranes from transfected CHO-K1 cells expressing the human DAD2 or the human sstr subtypes. Values are from IPSEN (J E Taylor \& M D Culler).

\begin{tabular}{|c|c|c|c|c|c|c|}
\hline Compound & sstr1 & sstr2 & sstr3 & sstr4 & sstr5 & DAD2 \\
\hline SST 14 & 2.3 & 0.2 & 1.4 & 1.8 & 1.4 & ND \\
\hline Octreotide & 1140 & 0.6 & 34 & 7030 & 7.0 & ND \\
\hline BIM-23197 & 6016 & 0.2 & 27 & 897 & 9.8 & $>1000$ \\
\hline BIM-23268 & 12 & 28 & 5.5 & 36 & 0.4 & ND \\
\hline BIM-53097 & $>1000$ & $>1000$ & $>1000$ & $>1000$ & $>1000$ & 22 \\
\hline BIM-23244 & $>1000$ & 0.3 & 133 & $>1000$ & 0.7 & ND \\
\hline BIM-23АЗ87 & 293 & 0.2 & 77 & $>1000$ & 26 & 22 \\
\hline BIM-23A758 & 468 & 0.1 & 324 & $>1000$ & 27 & 13 \\
\hline BIM-23A760 & 622 & 0.03 & 160 & $>1000$ & 42 & 15 \\
\hline BIM-23A761 & 462 & 0.06 & 52 & $>1000$ & 3.7 & 27 \\
\hline BIM-23A765 & $>1000$ & 0.2 & 76 & $>1000$ & 7 & 9 \\
\hline
\end{tabular}

ND, not done. 
$70 \%$ ethanol. All drugs were stored at $-80^{\circ} \mathrm{C}$ as $10^{-3} \mathrm{~mol} / \mathrm{l}$ solutions. For each experiment, working solutions were made by diluting a fresh aliquot with culture medium.

\section{Detection of sstr and DAD2 mRNAs}

Total RNA was extracted from 30-60 mg tissue from each tumor using the RNAeasy isolation system (Qiagen, Courtaboeuf, France). One microgram of total RNA prepared from tumoral pituitary tissues was used for cDNA synthesis, as previously described (8). To quantify sstr and DAD2 mRNAs, a quantitative PCR was performed by TaqMan Gold nuclease assay (Perkin Elmer, Foster City, CA, USA) and the ABI PRISM 7700 sequence Detection System (Perkin Elmer) for real-time amplifications, according to the manufacturer's protocol. The sstr and DAD2 mRNA levels were normalized to the $\beta$-glucuronidase ( $\beta$-Gus) mRNA levels obtained in the same reaction, as previously described (8). For each measurement, three independent RT-PCR analyses were performed.

\section{Cell culture studies}

A portion of each tumor obtained at surgery was dissociated by enzymatic and mechanical methods. Depending on the tumor, $7-50 \times 10^{6}$ isolated cells were obtained. These cells were plated in multiwell culture dishes (Costar 3524; Costar, Brumath, France) which were coated with extracellular matrix from bovine endothelial corneal cells, as previously described (10), at a density of $2 \times 10^{4}$ cells per well in Dulbecco's minimum Eagles' medium supplemented with $1 \%$ fetal calf serum, antibiotics, insulin, transferrin and selenium. The pharmacological studies were performed between days 4 and 8 of culture. Octreotide, the biselective sstr2-sstr5 SST analog, BIM-23244, and the SST-DA chimeric molecule, BIM-23A387, were tested at concentrations ranging from -13 to $-8 \mathrm{~mol} / \mathrm{l}$ in order to examine the dose-response relationship and to determine the $\mathrm{EC}_{50}$ for $\mathrm{GH}$ inhibition. In six of these tumor cell cultures, we compared the dose-response inhibition of GH secretion (and PRL in four GH-PRL tumors) achieved by the four new chimeric molecules with differing, enhanced affinity for sstr2, sstr 5 and DAD2 subtypes. In the same experiments, we also directly compared the dose-responses for $\mathrm{GH}$ achieved by octreotide and the original SST-DA chimeric molecule, BIM-23A387.

\section{Statistics}

The results are presented as the means \pm S.E.M. Statistical significance between two unpaired groups was determined by the Mann-Whitney test. To measure the strength of association between the pairs of variables without specifying dependencies, Spearman order correlations were used. $P<0.05$ was considered significant for all tests.

\section{Results}

\section{DAD2 and sstr subtype mRNA expression}

Real-time PCR quantitative analysis was performed on 15 out of 18 tumor fragments. The mean sstr 2 , sstr 5 and DAD2 mRNA levels were $0.4 \pm 0.1,5.3 \pm 1.9$ and $2.0 \pm 0.4$ copy/copy $\beta$-Gus respectively. The mean sstr 2 , sstr 5 and DAD2 mRNA levels were also measured in nine other $\mathrm{GH}$-secreting adenomas from patients classified as sensitive to octreotide, as they had achieved normal GH and IGF-I values under octreotide or lanreotide. These values were $1.7 \pm 0.3,4.8 \pm 0.7$ and $4.0 \pm 0.5$ copy/copy $\beta$-Gus respectively. The mean sstr2 mRNA level in tumors from patients partially responsive to octreotide was markedly lower than that from octreotide-sensitive patients $(P<0.001)$. Sstr 5 and DAD2 mRNA were well expressed in all tumors from patients partially responsive to octreotide and did not differ statistically from the level observed in tumors from octreotide-sensitive patients. No correlation between the response to treatment and the level of sstr 5 or DAD2 expression could be established.

\section{Maximal GH suppression by octreotide, SST and DA analogs}

The effect of octreotide and selective SST and DA analogs on GH secretion in cultured cells derived from the 18 tumors was measured after a 12 -h incubation period. The maximal inhibition of $\mathrm{GH}$ release induced by 1 or $10 \mathrm{nmol} / \mathrm{l}$ octreotide, as compared with controls (medium alone), was only partial and ranged from 6 to $35 \%$ according to the individual tumor (mean GH suppression by octreotide $23 \pm 3 \%$ ). When the 18 cell cultures were treated with the sstr2-selective analog, BIM-23197, the sstr5-selective analog, BIM-23268 or the DAD2 compound, BIM-53097, a mean maximal inhibition of GH release of $24 \pm 3,20 \pm 3$ and $20 \pm 3 \%$ respectively was obtained. Of the three compounds, BIM-23197 produced the greatest maximal GH suppression in the majority (12 out of 18) of cases. However, the greatest absolute maximal GH suppression was obtained with the DAD2 analog, BIM-53097, in four tumors and with the sstr5-preferring compound, BIM-23268, in two cases.

\section{Dose-related GH suppression with octreotide, the biselective sstr2-sstr 5 analog, BIM-23244, and the chimeric sstr2-DAD2 analog, BIM- 23A387}

In the 18 octreotide partially responsive tumors, octreotide, BIM-23244 and BIM-23A387 were tested at various concentrations to determine their respective 


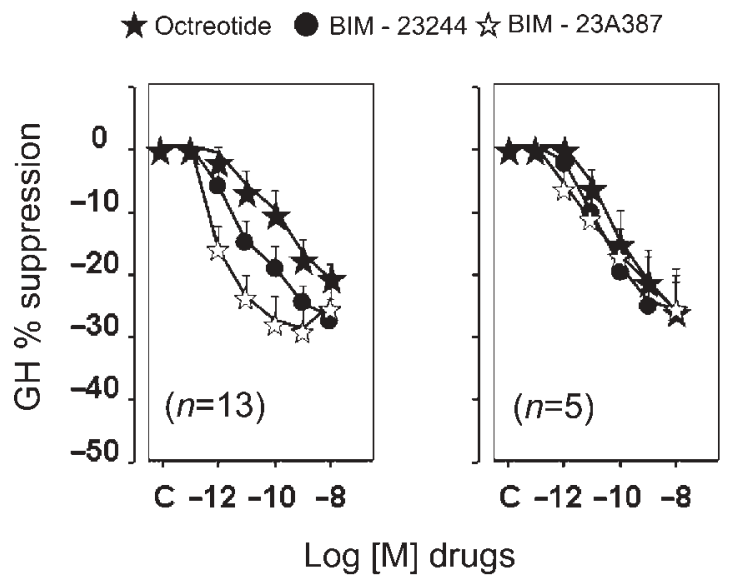

Figure 1 Mean dose-related GH suppression in cell cultures from 18 adenomas collected from acromegalic patients classified as partially responsive to octreotide. (Left panel) Dose-related GH suppression obtained in 15 tumors (group 1)with greater GH suppression with BIM-23244 and BIM-23A387 than with octreotide. (Right panel) Dose-related GH suppression obtained in five tumors (group 2) equally responsive to BIM-23244, BIM-23A387 and octreotide. Results are expressed as mean \pm S.E.M. percent $\mathrm{GH}$ suppression vs control ( $\mathrm{C}=$ medium alone). Each point represents the mean of four replicate wells.

potencies in suppressing GH secretion. Two individual patterns of dose-related inhibition of $\mathrm{GH}$ release were identified, as shown in Fig. 1. In the first group, consisting of 13 out of 18 tumors, the biselective molecules, BIM-23244 and BIM-23A387, at nanomolar concentrations, produced maximal mean GH suppression of $28 \pm 3$ and $30 \pm 3 \%$ respectively, greater by $23-43 \%$ than that obtained with octreotide $(21 \pm 2 \%$; $P<0.04$ and $P<0.01$ for BIM-23244 and BIM$23 \mathrm{~A} 387$ vs octreotide). The $\mathrm{EC}_{50}$ values for octreotide, BIM-23244 and BIM-23A387 were $150 \mathrm{pmol} / \mathrm{l}$ (range $6-250$ ), $10 \mathrm{pmol} / \mathrm{l}$ (range $2-100$ ) and $1 \mathrm{pmol} / \mathrm{l}$ (range $0.5-50)$ respectively. The comparison between the hybrid molecules showed a significantly $(P<0.05)$ better GH suppressive effect with BIM-23A387. The second group consisted of five tumors that displayed similar dose-response curves for GH suppression with octreotide, BIM-23244 and BIM-23A387. The differences between the $\mathrm{EC}_{50}$ values for octreotide, BIM23244 and BIM-23A387 (8020 pmol/l) did not reach statistical significance.

\section{Effects of new chimeric molecules with differing, enhanced affinities for sstr2, sstr 5 and DAD2 on GH suppression}

Cell cultures from six tumors from the first group that displayed enhanced inhibition of $\mathrm{GH}$ release with the sstr2-DAD2 compound, BIM-23A387, were used to test a series of four new chimeric molecules with differing, enhanced affinities for sstr2, sstr5 and DAD2 in order to find out if altering the activity ratio of these

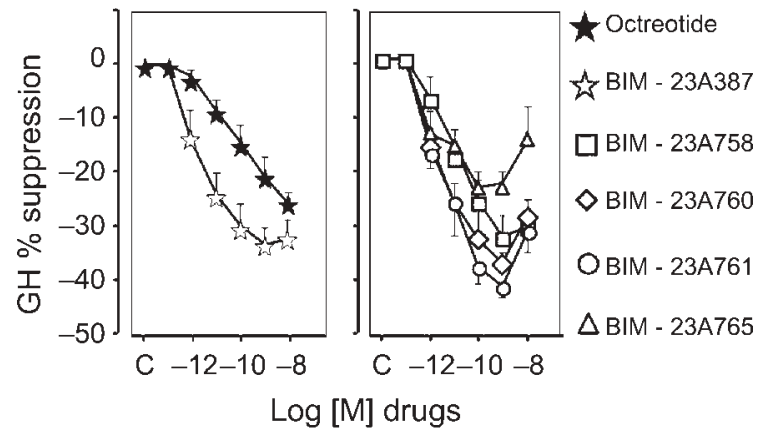

Figure 2 Mean dose-related GH suppression obtained with the trihybrid compounds, BIM-23A758, BIM-23A760, BIM-23A761 and BIM-23A765, in cell cultures from six adenomas that were partial responders to octreotide. (Left panel) Mean dose-related GH suppression with octreotide and BIM-23A387. (Right panel) Mean dose-related $\mathrm{GH}$ suppression obtained with four new chimeric molecules (BIM-23A758, BIM-23A760, BIM-23A761 and BIM23A765). Results are expressed as mean \pm S.E.M. percent GH suppression vs control $(\mathrm{C}=$ medium alone $)$. Each point represents the mean of four wells.

three receptors could produce a higher suppression of $\mathrm{GH}$ secretion than the activation produced by the original sstr2-DAD2 compound, BIM-23A387. As shown in Fig. 2, the mean maximal $\mathrm{GH}$ suppression achieved with the new chimeric compounds, BIM-23A758, BIM-23A760, BIM-23A761 and BIM-23A765, varied between $24 \pm 1$ and $41 \pm 2 \%$. The mean maximal GH suppression obtained with BIM-23A765 was similar to that obtained in the same tumors with octreotide $(26 \pm 2 \%)$. The mean maximal GH suppression obtained with the three other new chimeric compounds was significantly greater than that obtained with octreotide $(33 \pm 5,37 \pm 1$ and $41 \pm 2 \%$ with BIM-23A758, BIM23A760 and BIM-23A761; $P<0.05, P<0.03$, and $P<0.03$ respectively vs octreotide). The $\mathrm{EC}_{50}$ values for these three compounds ranged from 2 to $10 \mathrm{pmol} / \mathrm{l}$.

In these tumor cell cultures, the dose-related inhibition of GH secretion was also compared with that obtained with the original sstr2-DAD2 compound, BIM-23A387. As shown in Fig. 2, a mean suppression of $\mathrm{GH}$ release of $41 \pm 2 \%$ was obtained with BIM$23 \mathrm{~A} 761$ vs $32 \pm 4 \%$ for BIM-23A387 $(P<0.05)$ and $26 \pm 2 \%$ for octreotide $(P<0.01)$.

\section{BIM-23A761 vs the combination of sstr2, sstr 5 and DAD2 monospecific drugs}

In one tumor cell culture, the GH suppressive effect of the chimeric compound, BIM-23A761, was compared with an equimolar combination of the monospecific sstr2-, sstr5- and DAD2-preferential compounds. As shown in Fig. 3, the mean dose-related pattern of GH suppression produced by BIM-23A761 was markedly distinct from that induced by the combination of BIM-23197 + BIM-23268 + BIM-53097 with a mean maximal GH suppression of $49 \pm 3$ and $38 \pm 2 \%$ 


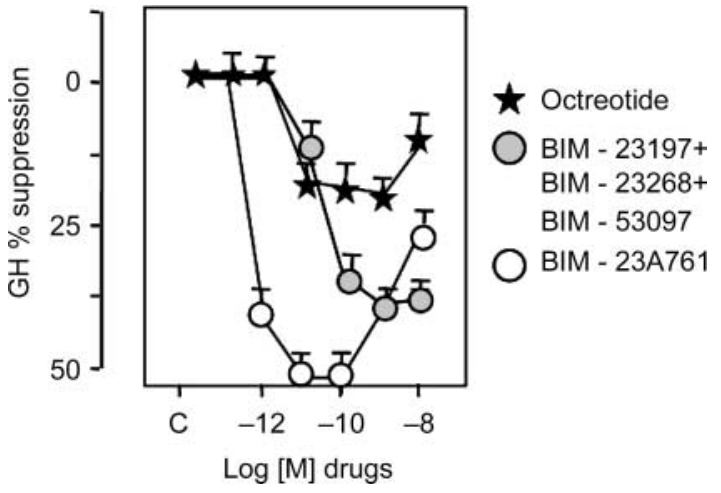

Figure 3 Mean dose-related GH suppression with BIM-23A761, the combination of BIM-23197 + BIM-23268 + BIM-53097 and octreotide in one adenoma that was partially responsive to octreotide. Results are expressed as the mean of four wells \pm S.E.M. percent $\mathrm{GH}$ suppression vs control $(\mathrm{C}=$ medium alone $)$. Each point represents the mean of four wells.

respectively $(P<0.03)$. Again the superior suppression of $\mathrm{GH}$ secretion by the chimeric molecule, as compared with octreotide (maximal suppression $22 \pm 2 \%$ ), was highly significant $(P<0.01)$.

\section{Effects of the DA-SST chimeric compounds on PRL release}

Dose-related inhibition of PRL secretion by the trihybrid compounds, BIM-23A758, BIM-23A760, BIM23A761 and BIM-23A765, was analyzed in cell cultures of four different GH + PRL-secreting tumors. As shown in Fig. 4, all the compounds were highly effective in suppressing PRL secretion (mean EC-50 values $=2-10 \mathrm{pmol} / \mathrm{l}$; maximal suppression $68 \pm 10$ to $74 \pm 4 \%$, depending on the compound). In comparison, octreotide and the original, chimeric compound, BIM-23A387, produced only $45 \pm 11$ and $54 \pm 8 \%$

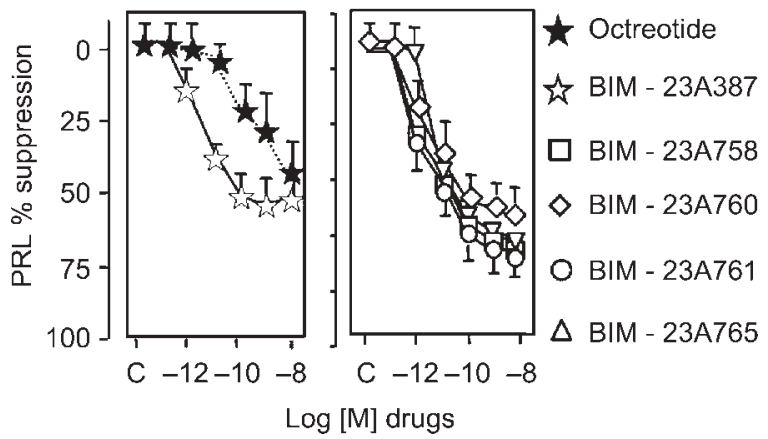

Figure 4 Mean dose-related PRL suppression obtained with the trihybrid compounds, BIM-23A758, BIM-23A760, BIM-23A761 and BIM-23A765, in cell cultures from four mixed GH-PRL adenomas. (Left panel) Dose-response GH suppression by octreotide and BIM-23A387. (Right panel) Dose-response GH suppression by the four new, multi-receptor-interacting chimeras. Results are expressed as mean \pm S.E.M. percent PRL suppression vs control $(\mathrm{C}=$ medium alone $)$. Each point represents the mean of four replicate wells. maximal inhibition of PRL secretion, with $\mathrm{EC}_{50}$ values of 200 and $5 \mathrm{pmol} / \mathrm{l}$ respectively.

\section{Discussion}

Acromegalic patients classified as only partially responsive to long-term therapy with octreotide or lanreotide represent $40-50 \%$ of the total patient population (1). They are defined by a failure to achieve normalization of GH and IGF-I plasma levels despite at least 3-6 months of treatment with high doses of octreotide or lanreotide. Such a partial response is a primary phenomenon not linked to tachyphylaxis, as observed with other neuroendocrine tumors (11). It appears to be linked to a selective loss of sstr2 expression (12, 13). The analysis of sstr 2 , sstr 5 and DAD 2 mRNA profiles in the present series of tumors confirms such a selective loss of sst2r. In recent years, the additive effect of combined sstr 2 and sstr 5 preferential compounds on GH suppression, in tumors partially responsive to octreotide, has been demonstrated in cell culture studies $(7,13,14)$. This finding led to the introduction of the sstr2-sstr5 dihybrid compound, BIM-23244 (7, 15). The improved GH-suppressive effect was interpreted as a rescue of response acting through the highly expressed sstr 5 in tumors expressing low levels of sstr2 (7). The present data confirmed, in about $72 \%$ of $\mathrm{GH}$-secreting tumors, a lower $\mathrm{EC}_{50}$ and a higher maximal GH suppression for BIM-23244 as compared with octreotide. The reasons why some octreotide-resistant tumors do not display enhanced sensitivity to the bispecific molecule are presently unknown. Recently, another new SST analog that interacts with sstr1, sstr2, sstr3, but mainly with sstr $5\left(\mathrm{IC}_{50}\right.$ for sstr $\left.50.16 \mathrm{nmol} / \mathrm{l}\right)$, SOM230, has also been reported to exhibit enhanced potency in suppressing GH and PRL secretion from some GH-secreting tumors that are partial responders to octreotide, both in vitro and in vivo $(13,16)$. Taken together, these studies indicate that new somatostatinergic drugs directed towards different sstrs can achieve a better $\mathrm{GH}$ suppression than octreotide in some acromegalic tumors.

DA agonists were the first drugs used in the medical treatment of acromegaly. The efficacy of dopaminergic treatment increased to reach $29-39 \%$ of patients with the advent of the high affinity D2 analog, cabergoline $(3,4)$. Until recently, it was believed that only GHPRL mixed tumors could be controlled by cabergoline; however, a recent study demonstrated that the efficacy of adding cabergoline treatment in $42 \%$ of patients partially responsive to octreotide or lanreotide therapy was independent of PRL status (5). In our study, as in previous studies $(8,17)$, the chimeric molecule, BIM23A387, displayed enhanced potency in suppressing GH secretion in the 13 out of 18 cell culture studies. In another study, using the antagonists sulpiride and BIM-23454, which antagonize DAD2 and sstr2 
respectively, the higher efficacy of BIM-23A387 was attributed in large part to its dopaminergic pharmacophore site (17). We have previously demonstrated that both antagonists were able to partially reverse the activity of BIM-23A387 (8). Such apparently contradictory results can be explained by the different conditions used in the two studies. Because the sstr2 antagonist, BIM-23454 (18), has a low affinity for sstr2 $\left(\mathrm{IC}_{50} 32 \mathrm{nmol} / \mathrm{l}\right)$ as compared with that of BIM$23 \mathrm{~A} 387\left(\mathrm{IC}_{50} 0.16 \mathrm{nmol} / \mathrm{l}\right)$, it can reverse the action of BIM-23A387 when BIM-23A387 is used at picomolar concentrations (8) and not at a higher concentration of $4 \mathrm{nmol} / \mathrm{l}$ (17). Finally, when the doserelated inhibition of GH secretion attained with BIM23A387 and with BIM-23244 were compared, BIM$23 \mathrm{~A} 387$ displayed an $\mathrm{EC}_{50}$ ten times lower than that of BIM-23244.

The second part of our study explored the possibility of a further enhancement of GH suppression from GHsecreting tumors partially responsive to octreotide by using new chimeric molecules that have differing, enhanced activities at sstr2, sstr5 and DAD2. From 12 different compounds, four such chimeric molecules with variable affinities for each receptor were selected. All four of these compounds displayed an exceptionally high affinity for sstr2 ( $\left.\mathrm{IC}_{50} 10-100 \mathrm{pmol} / \mathrm{l}\right)$. In the tumors treated with these compounds, in cell culture, $\mathrm{GH}$ secretion was suppressed with an $\mathrm{EC}_{50}$ significantly lower than that achieved with octreotide (1-10 vs $80 \mathrm{pmol} / \mathrm{l})$. Three of the four new chimeric molecules also induced maximal GH suppression that was significantly greater than that produced by octreotide. Finally, the most potent sstr2-interacting chimeric molecules produced the greatest maximal GH inhibition. An increase in sstr2-binding affinity has previously been achieved with a non-peptide selective agonist, L-054522, which binds to the human sstr2 with a reported $K_{\mathrm{i}}$ of $0.01 \mathrm{nmol} / \mathrm{l}$ (19). High binding affinity for sstr2 is apparently a key point in the higher efficacy of the chimeric compounds; however, it does not completely explain the greater $\mathrm{GH}$-suppressing efficacy of the new chimeric compounds since, among our compounds, BIM-23A765, despite its high affinity for sstr2, did not suppress GH secretion more efficiently than octreotide. It has been hypothesized that such multiple ligands could induce receptor homo- and hetero-dimerization as experimentally demonstrated in transfected cell lines $(6,20-22)$. The first evidence that such a heterodimerization process may occur in normal cells was presented in a study using fluorescence resonance energy transfer (FRET) in cortical neurons in culture (23). Another explanation for the greater efficacy of the multi-receptorinteracting chimeric compounds could be due to a different interaction between the ligand and its receptor that allows prolonged stabilization of its active conformation or alternation of the rate of internalization (24-26). Accordingly, a $\beta$-arrestin-dependent recycling of the sstr 2 to the plasma membrane that may prevent sstr2 but not sstr 5 degradation has recently been described using sstr2-transfected HEK293 cells (27). One final explanation for the greater potency of the multi-receptor-interacting chimeric molecules may simply be due to the fact that they can bind and activate multiple receptors. This ability increases the chance that once the ligand is released from one receptor it will rapidly occupy another receptor. Presently, there is no firm explanation for the unique activities of these novel chimeric compounds, and additional studies, such as those using fluorescent SST analogs or FRET, as recently studied in live adrenocorticotropin-secreting AtT20 cells (28), are needed to explain the enhanced efficiency of these ligands.

In conclusion, our present study extends the notion that ligands directed towards both DA and SST receptors can achieve greater hormone (GH and PRL) suppression than that achieved by octreotide in human GH-secreting adenomas. These new chimeric molecules may represent a new concept in drug design allowing greater efficacy in the treatment of a wider range of acromegalic patients. Indeed, clinical studies are needed in order to evaluate the tolerance of such compounds.

\section{Acknowledgements}

The skillful help of Mrs C Taverna in the editing of the manuscript was greatly appreciated. We are grateful to Mrs S Guillen for technical help. This work was supported by a grant from Biomeasure, Inc. (Milford, MA, USA) and by the Association pour le Développement et la Recherche Médicale (Marseille, France).

\section{References}

1 Freda PU. Somatostatin analogs in acromegaly. Journal of Clinical Endocrinology and Metabolism 200287 3013-3018.

2 Liuzzi A, Chiodini PG, Botalla L, Cremascoli G \& Silvestrini F. Inhibitory effect of L-Dopa on GH release in acromegalic patients. Journal of Clinical Endocrinology and Metabolism 197235 941-943.

3 Cozzi R, Attanasio R, Barausse M, Dallabonzana D, Orlandi P, Da Re N, Branca V, Oppizzi G \& Gelli D. Cabergoline in acromegaly: a renewed role for dopamine agonist treatment? European Journal of Endocrinology $1998139516-521$.

4 Abs R, Verhelst J, Maiter D, Van Acker K, Nobels F, Coolens JL, Mahler $\mathrm{C} \&$ Beckers A. Cabergoline in the treatment of acromegaly: a study in 64 patients. Journal of Clinical Endocrinology and Metabolism $1998 \mathbf{8 3} 374-378$.

5 Marzullo P, Ferone D, Di Somma C, Pivonello R, Filippella M, Lombardi G \& Colao A. Efficacy of combined treatment with lanreotide and cabergoline in selected therapy-resistant acromegalic patients. Pituitary 19991 115-120.

6 Rocheville M, Lange DC, Kumar U, Patel SC, Patel RC \& Patel YC. Receptors for dopamine and somatostatin: formation of heterooligomers with enhanced functional activity. Science $2000 \mathbf{2 8 8}$ $154-157$.

7 Saveanu A, Gunz G, Dufour H, Caron P, Fina F, Ouafik L, Culler MD, Moreau JP, Enjalbert A \& Jaquet P. Bim-23244, a somatostatin receptor subtype 2-and 5-selective analog with 
enhanced efficacy in suppressing growth hormone (GH) from octreotide-resistant human GH-secreting adenomas. Journal of Clinical Endocrinology and Metabolism 2001 86 140-145.

8 Saveanu A, Lavaque E, Gunz G, Barlier A, Kim S, Taylor JE, Culler MD, Enjalbert A \& Jaquet P. Demonstration of enhanced potency of a chimeric somatostatin-dopamine molecule, BIM23A387, in suppressing growth hormone and prolactin secretion from human pituitary somatotroph adenoma cells. Journal of Clinical Endocrinology and Metabolism 200287 5545-5552.

9 Taylor JE, Nelson R \& Woon CW. Real-time evaluation of somatostatin subtype 2 receptor activity employing the technique of cytosensor microphysiometry. Peptides $1996171257-1259$.

10 Jaquet P, Gunz G \& Grisoli F. Hormonal regulation of prolactin release by human prolactinoma cells cultured in serum-free conditions. Hormone Research 198522 153-163.

11 Hofland LJ \& Lamberts SW. The pathophysiological consequences of somatostatin receptor internalization and resistance. Endocrine Reviews $20032428-47$.

12 Jaquet P, Saveanu A, Gunz G, Fina F, Zamora AJ, Grino M, Culler MD, Moreau JP, Enjalbert A \& Ouafik LH. Human somatostatin receptor subtypes in acromegaly: distinct patterns of messenger ribonucleic acid expression and hormone suppression identify different tumoral phenotypes. Journal of Clinical Endocrinology and Metabolism $2000 \mathbf{8 5} 781-792$.

13 Hofland LJ, van der Hoek J, van Koetsveld PM, de Herder WW, Waaijers M, Sprij-Mooij D, Bruns C, Weckbecker G, Feelders R, van der Lely AJ, Beckers A \& Lamberts SW. The novel somatostatin analog SOM230 is a potent inhibitor of hormone release by growth hormone-and prolactin-secreting pituitary adenomas in vitro. Journal of Clinical Endocrinology and Metabolism 200489 1577-1585.

14 Shimon I, Yan X, Taylor JE, Weiss MH, Culler MD \& Melmed S. Somatostatin receptor (SSTR) subtype-selective analogues differentially suppress in vitro growth hormone and prolactin in human pituitary adenomas. Novel potential therapy for functional pituitary tumors. Journal of Clinical Investigation 1997 $1002386-2392$.

15 Ren SG, Taylor J, Dong J, Yu R, Culler MD \& Melmed S. Functional association of somatostatin receptor subtypes 2 and 5 in inhibiting human growth hormone secretion. Journal of Clinical Endocrinology and Metabolism $2003 \mathbf{8 8} 4239-4245$.

16 Van Der Hoek J, De Herder WW, Feelders RA, Van Der Lely AJ, Uitterlinden $\mathrm{P}$, Boerlin V, Bruns C, Poon KW, Lewis I, Weckbecker G, Krahnke T, Hofland LJ \& Lamberts SW. A singledose comparison of the acute effects between the new somatostatin analog SOM230 and octreotide in acromegalic patients. Journal of Clinical Endocrinology and Metabolism 200489 638-645.

17 Ren SG, Kim S, Taylor J, Dong J, Moreau JP, Culler MD \& Melmed S. Suppression of rat and human growth hormone and prolactin secretion by a novel somatostatin/dopaminergic chimeric ligand. Journal of Clinical Endocrinology and Metabolism $2003 \mathbf{8 8}$ 5414-5421.
18 Tulipano G, Soldi D, Bagnasco M, Culler MD, Taylor JE, Cocchi D \& Giustina A. Characterization of new selective somatostatin receptor subtype-2 (sst2) antagonists, BIM-23627 and BIM23454. Effects of BIM-23627 on GH release in anesthetized male rats after short-term high-dose dexamethasone treatment. Endocrinology $20021431218-1224$.

19 Yang L, Guo L, Pasternak A, Mosley R, Rohrer S, Birzin E, Foor F, Cheng K, Schaeffer J \& Patchett AA. Spiro[1H-indene-1,4'-piperidine] derivatives as potent and selective non-peptide human somatostatin receptor subtype 2 (sst2) agonists. Journal of Medicinal Chemistry $1998 \mathbf{4 1}$ 2175-2179.

20 Rocheville M, Lange DC, Kumar U, Sasi R, Patel RC \& Patel YC. Subtypes of the somatostatin receptor assemble as functional homo-and heterodimers. Journal of Biological Chemistry 2000 $2757862-7869$

21 Pfeiffer M, Koch T, Schroder H, Klutzny M, Kirscht S, Kreienkamp HJ, Hollt V \& Schulz S. Homo-and heterodimerization of somatostatin receptor subtypes. Inactivation of sst(3) receptor function by heterodimerization with sst(2A). Journal of Biological Chemistry 2001276 14027-14036.

22 Pfeiffer M, Koch T, Schroder H, Laugsch M, Hollt V \& Schulz S. Heterodimerization of somatostatin and opioid receptors crossmodulates phosphorylation, internalization, and desensitization. Journal of Biological Chemistry 2002277 19762-19772.

23 Baragli A, Kumar U, Patel RC \& Patel YC. Hetero-oligomerisation of dopamine (D2R) and somatostatin receptors (sstr2) in CHO-K1 cells and cortical cultures neurons. In Proceedings of the 85th Annual Meeting of the Endocrine Society. Philadelphia, 2003, p 469.

24 Patel RC, Kumar U, Lamb DC, Eid JS, Rocheville M, Grant M, Rani A, Hazlett T, Patel SC, Gratton E \& Patel YC. Ligand binding to somatostatin receptors induces receptor-specific oligomer formation in live cells. PNAS $2002993294-3299$.

25 Moller LN, Stidsen CE, Hartmann B \& Holst JJ. Somatostatin receptors. Biochimica et Biophysica Acta $200316161-84$.

26 Grant M, Patel RC \& Kumar U. The role of subtype-specific ligand binding and the C-tail domain in dimer formation of human somatostatin receptors. Journal of Biological Chemistry 2004279 38636-38643.

27 Tulipano G, Stumm R, Pfeiffer M, Kreienkamp HJ, Hollt V \& Schulz S. Differential beta-arrestin trafficking and endosomal sorting of somatostatin receptor subtypes. Journal of Biological Chemistry $200427921374-21382$.

28 Ben-Shlomo A, Miklovsky I, Wawrowsky KA, Ren SG, Taylor J, Culler MD \& Melmed S. Visualization and function of pituitary receptor subtypes in live ACTH-secreting AtT20 cells. In Proceedings of the 85th Annual Meeting of the Endocrine Society. New Orleans, 2004, pp P3-244.

Received 10 March 2005

Accepted 13 April 2005 